\title{
Liver-directed Therapy
}

National Cancer Institute

\section{Source}

National Cancer Institute. Liver-directed Therapy. NCI Thesaurus. Code C162161.

Any therapy designed to treat the liver while sparing nearby tissues and organs.

Treatment modalities include hepatic arterial infusion, embolization therapies, selective internal radiation therapy, and stereotactic body radiation therapy. 